\title{
Acute Volvulus of a Wandering Spleen on Pregnancy: A Case Report
}

\author{
Traoré Mamadou1*, Kouakou Kouamé Bernadin1, Anzoua Kouakou Ibrahim', \\ Menin Messou Benié Michelle2, Djahan Lydie Estelle², Leh Bi Kalou Ismaêl1, \\ N'Dri Ahou Bernadette', Ekra Amos Serges' ${ }^{1}$, Kouakou Blaise Amos', \\ Zouan Freddy Junior ${ }^{1}$, Lebeau Roger ${ }^{1}$, Diané Bamourou ${ }^{1}$
}

\footnotetext{
${ }^{1}$ Digestive Surgery Department, University Hospital of Bouaké, Bouaké, Côte d'Ivoire ${ }^{2}$ Gyneco-Obstetrics Department, University Hospital of Bouaké, Bouaké, Côte d'Ivoire Email: *traorefallstam2000@yahoo.fr
}

How to cite this paper: Mamadou, T., Bernadin, K.K., Ibrahim, A.K., Michelle, M.M.B., Estelle, D.L., Ismaêl, L.B.K., Bernadette, N.A., Serges, E.A., Amos, K.B., Freddy Junior, Z., Roger, L. and Bamourou, D. (2018) Acute Volvulus of a Wandering Spleen on Pregnancy: A Case Report. Open Journal of Obstetrics and Gynecology, 8, 300-305.

https://doi.org/10.4236/ojog.2018.84032

Received: November 30, 2017

Accepted: April 1, 2018

Published: April 4, 2018

Copyright ( 2018 by authors and Scientific Research Publishing Inc. This work is licensed under the Creative Commons Attribution International License (CC BY 4.0).

http://creativecommons.org/licenses/by/4.0/

\begin{abstract}
Wandering or ectopic spleen is a rare congenital or acquired abnormality due to a defect in the anatomical fixity of the spleen with the surrounding organs. Pedicle twisting is its most common complication. It is an anatomo-clinical entity most often described in children, but rare in adults. It is a serious condition, especially when it occurs on a pregnancy putting at stake maternal and fetal prognosis. Authors report a case of acute volvulus of wandering spleen in a 26-year-old patient admitted for abdominal pain on an active pregnancy of 15 weeks of amenorrhea. Abdominal ultrasound scan helped to set the diagnosis. At laparotomy, the enlarged spleen was in an ectopic position, in the iliac fossa with a pedicle abnormally twisted in several spiral turns. Splenectomy was performed. The post-operative period was simple and the pregnancy progressed well to term.
\end{abstract}

\section{Keywords}

Wandering Spleen, Volvulus, Pregnancy, Splenectomy

\section{Introduction}

Wandering or ectopic spleen is a congenital or acquired abnormality due to lack in the anatomical fixity of the spleen with the surrounding organs, which means that the spleen can be found in any quadrant of the abdomen. Acute volvulus, the most dreadful complication of this anomaly, is twisting of the spleen around its vascular axis in one or more spiral turns. It brings about permanent splenic vascular occlusion leading to ischemia and then splenic necrosis. Acute volvulus 
wandering spleen is an anatomo-clinical entity most often described in children [1] [2] [3], rare in adults with a slight female predominance [4]. It can also occur on a pregnancy [5]. In this case, it puts maternal and fetal prognosis at stake. It is then a digestive and obstetric surgical emergency. Because of high recurrence after splenopexy and the advent of vaccines that lowered the risk of overwhelming postsplenectomy sepsis, Splenectomy is very often carried out [5]. We report a case of acute volvulus of wandering spleen on pregnancy insisting on the emergency of the diagnosis and specific treatment.

\section{Observation}

A 26-year-old patient, a housewife, living in the countryside, with a pregnancy estimated at 15 weeks of amenorrhea, was admitted to the gyneco-obstetrics emergency service of the University Hospital of Bouake for an ongoing 3-day abdominal and pelvic pain associated with vomiting. There was not any bowel movement disorder, neither fever, nor metrorrhagia, nor urinary disturbance. With regard to the gynecological-obstetrical history, she was bearing her third pregnancy, and has already been mother of 2 healthy babies delivered naturally. For the current pregnancy, an antenatal visit was carried out at $12 \mathrm{SA}$ and there was nothing unusual. The medical history was marked by intermittent abdominal pain that had been developing for several years, but the patient had never undergone surgery.

At the entrance exam, the temperature at $37.4^{\circ} \mathrm{C}$, the blood pressure at $110 / 60$ $\mathrm{mmHg}$, and the pulse rate at $100 \mathrm{bpm}$. The right iliac fossa was arched Figure 1. The abdomen was entirely sensitive with a firm, not very mobile tender mass stretching from the right iliac fossa to the pelvis. At the gynecological-obstetric examination, the uterus was supra-pubic palpable, deviated to the left. There was lack of vaginal discharge, a softened, closed, and short posterior cervix. The hemoglobin level was $9 \mathrm{~g} / \mathrm{dl}$, and the white blood cell level was $12,000 / \mathrm{mm}^{3}$, and the platelet count was $370,000 \mathrm{~mm}^{3}$. The ultrasound (US) carried out as a matter of urgency showed a void in the splenic chamber and a heterogeneous mass

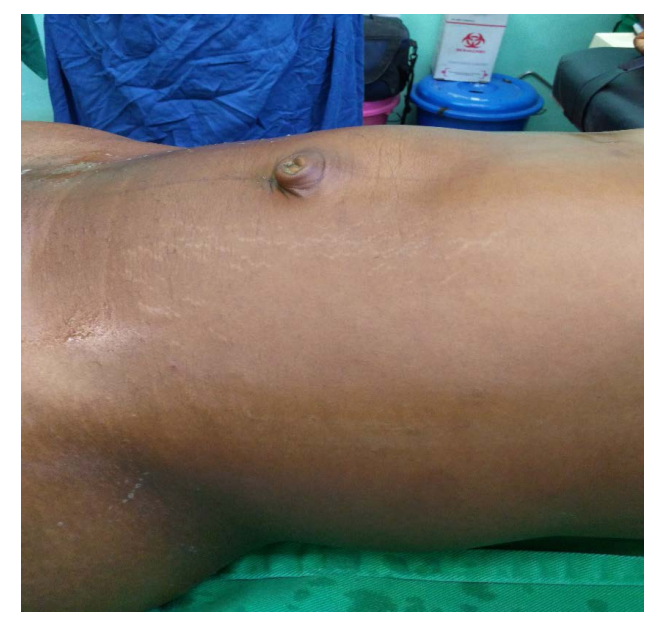

Figure 1. Arch of the right iliac fossa. 
of $22 \times 16 \mathrm{~cm}$ stretching from the right iliac fossa to the pelvis corresponding to an enlarged spleen in an ectopic position. The Doppler showed a lack of vascular flux at the spleen. The uterus was gravid with a progressive $15 \mathrm{SA}$ mono fetal pregnancy. Diagnosis of ectopic spleen on a progressive pregnancy was retained, and indicated exploratory laparotomy was stated. $300 \mathrm{cc}$ of hematic fluid was sucked out via median laparotomy. The spleen was voluminous and with ischemia, located in the lower right-hand part of the abdomen pushing back the gravid uterus Figure 2. The splenic pedicle was $50 \mathrm{~cm}$ long and twisted in several spiral turns in a clockwise direction Figure 3. Splenectomy was performed. The procedure was accompanied by an infusion of antispasmodic drugs. The

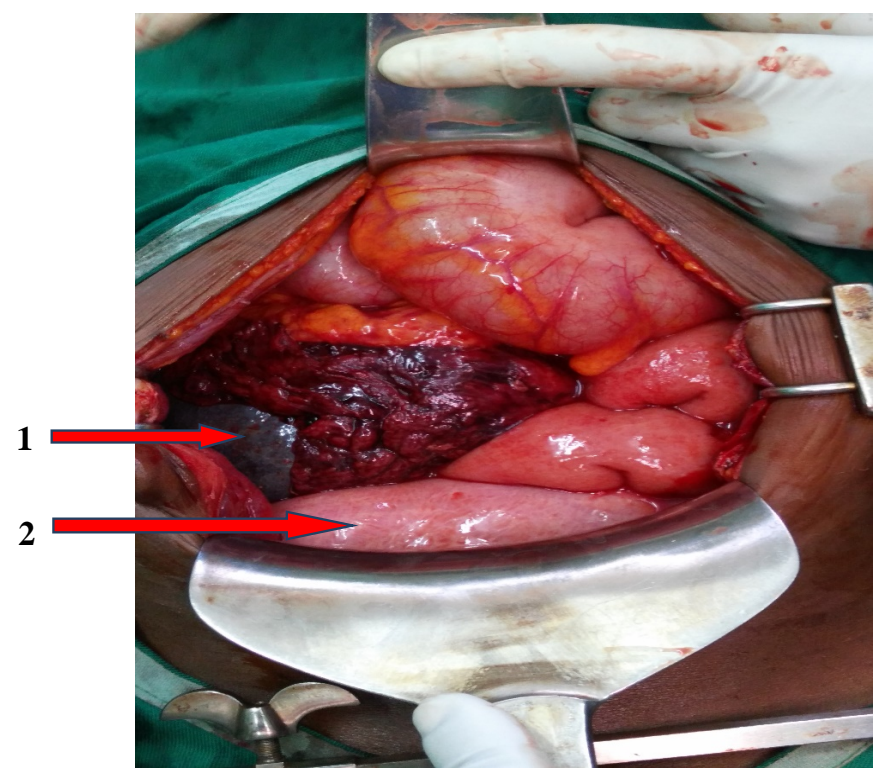

Figure 2. Enlarged spleen (1) located in the right iliac fossa to the pelvis compressing the gravid uterus (2) down.

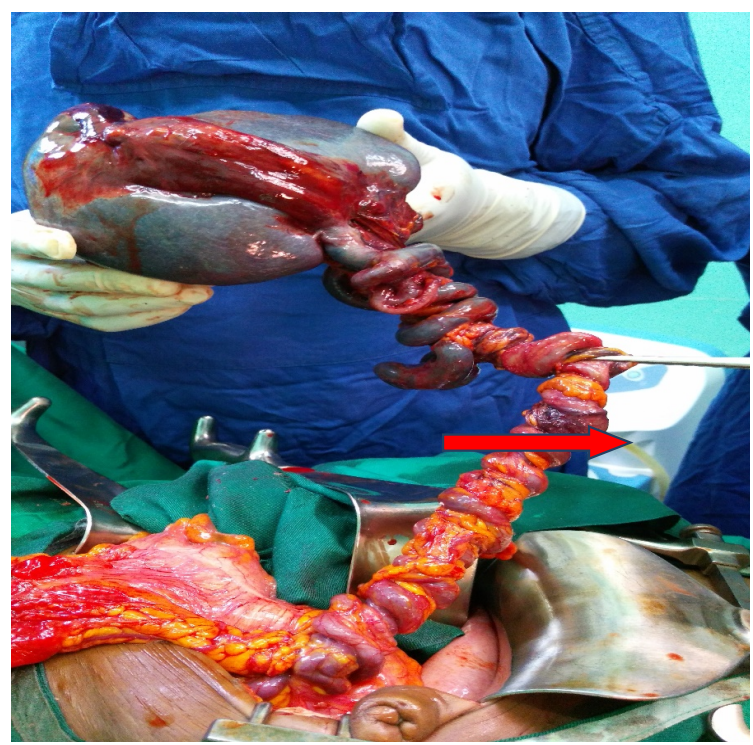

Figure 3. Spleen pedicle of $50 \mathrm{~cm}$ not joined and twisted in many spiral turns clockwise. 
aftermath of the operation was simple. The patient was discharged at day five after the operation. The anatomo-pathological examination showed an ischemic hyperplastic spleen with necrosis zones without any malignancy sign. Regular monitoring of the pregnancy allowed the eventual delivery of a newborn baby boy, APGAR 8 - 9, weight $3.1 \mathrm{~kg}$, height $53 \mathrm{~cm}$, head circumference $36 \mathrm{~cm}$. Oxacillin antibiotic prophylaxis was prescribed during pregnancy; and after delivery, vaccines to prevent fulminant infections (anti-meningococcal AC, anti-Hemophilus influenza and pneumo 23) were administered.

\section{Discussion}

Wandering spleen is a rare condition with an estimated $0.2 \%$ [4] [6] prevalence. It most commonly occurs in children [6] [7] but rarer in adults with a slight female predominance [4]. Abnormal mobility of the spleen is secondary to either hyperlaxity or congenital or acquired agenesis of the spleen suspense ligaments [2]-[8]. In our case, this was a congenital abnormality due to a failure of the posterior mesogastrium to bind together with a free splenic pedicle which lengthened gradually. Volvulus is favored by the spleen's weight, mobility and its pedicle's length [6]. Pregnancy is a rare risk factor for volvulus [2]-[9]. In our case, the pregnancy can be said to have prevented twisting; hence the acute presentation. Actually, so far the volvulus evolved in twisting-untwisting chronic mode.

Clinical symptomatology can be atypical, represented by intermittent or chronic abdominal pain that is indicative of spontaneous twisting and untwisting [3] [4] [5] [6], resulting in delayed diagnosis. In case of permanent twisting, the clinical picture is that of an acute surgical abdomen with severe abdominal pain, vomiting and fever. Abdominal palpation should be performed to look for peritoneal signs and a mobile abdominal or pelvic mass [6]. The acute abdominal table associated with a mobile and tender abdominal mass must evoke the diagnosis of a wandering spleen twisting; which was the case with our patient. This clinical presentation must entail an imaging examination as a matter of urgency, in particular an ultrasound, which is here the first-line imaging examination to confirm the diagnosis [6] [7] [8] [9] [10]. It makes it possible to affirm the diagnosis of wandering spleen twisting in the face of the emptiness of the splenic chamber and display of an abdominal mass whose echo-structure is that of the spleen and absence of vascularization with the Doppler [6]. In our case, ultrasound was used to diagnose and assess fetal vitality. In case of diagnostic difficulties with ultrasounds and especially in the presence of pregnancy, MRI is necessary. CT is only indicated if absolutely necessary due to teratogenic risk.

Volvulus of the spleen on pregnancy is a surgical and obstetric emergency putting maternal and fetal prognosis at stake. Treatment requires collaboration between gynecologists, surgeons and anesthesiologists. This collegial support enabled us to maintain both prognoses. The surgical procedure, monitored by a tocolysis protocol, depends on the spleen condition [3]. Actually, in the absence of spleen necrosis, untwisting and fixation of the spleen is carried out in its anatomical position (splenopexy). In the case of pathological spleen (necrosis, sple- 
nomegaly), splenectomy is indicated [3] [6] [11]. Because of high recurrence after splenopexy and the advent of vaccines that lowered the risk of overwhelming post splenectomy sepsis, most surgeons have chosen splenectomy for wandering spleen. Not to mention that splenectomy in these patients with a single pedicle free is technically quite easy [5]. In our patient, we performed a splenectomy because the spleen had areas of necrosis and the pedicle was free. Laparoscopy, which turned to be harmless to the pregnancy [5], was not used in our case because it was not available.

\section{Conclusion}

Volvulus of wandering spleen is a rare anatomo-clinical entity. It is a serious condition, especially when it occurs on a pregnancy putting the maternal and fetal prognosis at stake. Diagnosis must be early and rapid treatment requires good collaboration between gynecologists, surgeons and anesthesiologists.

\section{References}

[1] Navarro, R.D.C., Gomez, A.T. and Paz, P.S. (2003) Wandering Spleen Causing Acute Abdomen. Case Reports and Clinical Practice Review, 4, 173-175.

[2] Blanc, C., Delvaux, M., Aggadi, Y., Lagier, E., Gonzales, N. and Fourtanier, G. (1999) Infarctus de la rate par torsion du pédicule splénique: Syndrome de la rate baladeuse. Gastroenterologie Clinique Et Biologique, 23, 685-688.

[3] Yapo, P., Gnangoran, K.M., Doumbia, M., Lebeau, R., Assohoun, T. and Miessan, J.B.K. (2011) Volvulus d'une rate voyageuse chez l'adulte: à propos d'un cas au CHU de Yopougon (Abidjan-Côte-d'Ivoire). Journal Africain d'Hépato-Gastroentérologie, 5, 180-182. https://doi.org/10.1007/s12157-011-0272-4

[4] Sharma, A. and Salerno, G. (2014) A Torted Wandering Spleen: A Case Report. Journal of Medical Case Reports, 8, 133. https://doi.org/10.1186/1752-1947-8-133

[5] Yücel, E., Kurt, Y., Ozdemir, Y., Gun, I. and Yildiz, M. (2012) Laparoscopic Splenectomy for the Treatment of Wandering Spleen in a Pregnant Woman: A Case Report. Surgical Laparoscopy Endoscopy \& Percutaneous Techniques, 22, 102-104. https://doi.org/10.1097/SLE.0b013e318246beb5

[6] Dème, H., Akpo, L.G., Fall, S., Badji, N., Ka, I., Guèye, M.L. and Touré, M.H. (2016) Torsion chronique d'une rate baladeuse chez un adolescent: à propos d'un cas. Pan African Medical Journal, 24, 15. https://doi.org/10.11604/pamj.2016.24.15.7554

[7] Horwitz, J.R. and Black, C.T. (1996) Traumatic Rupture of a Wandering Spleen in a Child: Case Report and Literature Review. Journal of Trauma, 41, 348-350. https://doi.org/10.1097/00005373-199608000-00027

[8] Sodhi, K.S., Saggar, K., Sood, B.P. and Sandhu, P. (2003) Torsion of a Wandering Spleen: Acute Abdominal Présentation. The Journal of Emergency Medicine, 25, 133-137. https://doi.org/10.1016/S0736-4679(03)00160-4

[9] Khalid, E., Fatimazahra, B., Rachid, L., Abdelaziz, F., Mohamed, L., Nadia, B., et al. (2012) Acute Abdomen in a Torsion of an Ectopic Spleen: Report of a Case. Pan African Medical Journal, 11, 62.

[10] Karmazyn, B., Steinberg, R., Gayer, G. and Kornreich, L. (2005) Wandering Spleen-The Challenge of Ultrasound Diagnosis: Report of 7 Cases. Journal of Clinical Ultrasound, 33, 433-438. https://doi.org/10.1002/jcu.20165 
[11] Bouzaidi, K., Daghfous, A., Ben Ali, M., Karma, S. and Rezgui Marhou, L. (2014) Infarctus d'une rate baladeuse-A propos d'un cas. La Presse Médicale, 43, 225-228. https://doi.org/10.1016/j.lpm.2013.04.022 